\title{
Screw and cable actuators (SCS) and their applications to force feedback teleoperation, exoskeleton and anthropomorphic robotics
}

\author{
Philippe Garrec \\ CEA List \\ Interactive Robotics Unit \\ France
}

\section{Introduction}

Some years ago, the CEA developed a new actuator - the Screw and Cable System - to motorize a teleoperation force feedback master arm that would be more economical than previous machines such as the MA23 master arm, a pioneering machine originally designed in 1974 by Jean Vertut and his team also at CEA. The new master arm has been since industrialized and is now manufactured by Haption ${ }^{\circledR}$ under the name Virtuose ${ }^{\mathrm{TM}} 6 \mathrm{D}$ 40-40. Shorly after, we also designed, upon the same SCS actuator, a new force feedback slave arm for radioactive waste disposal inside a well (STeP: Système de Téléopération en Puits). After these achievements, we recognized that SCS could be interestingly integrated inside manipulator's articulated structure instead of being concentrated at its base. Our laboratory then engaged in the successful design of the upper limb exoskeleton today named ABLE. This is indeed a new type of anthropomorphic, open robot that also offers true linear torque capability without force sensor. A low inertia of the structure and motors altogether lead to a high transparency.
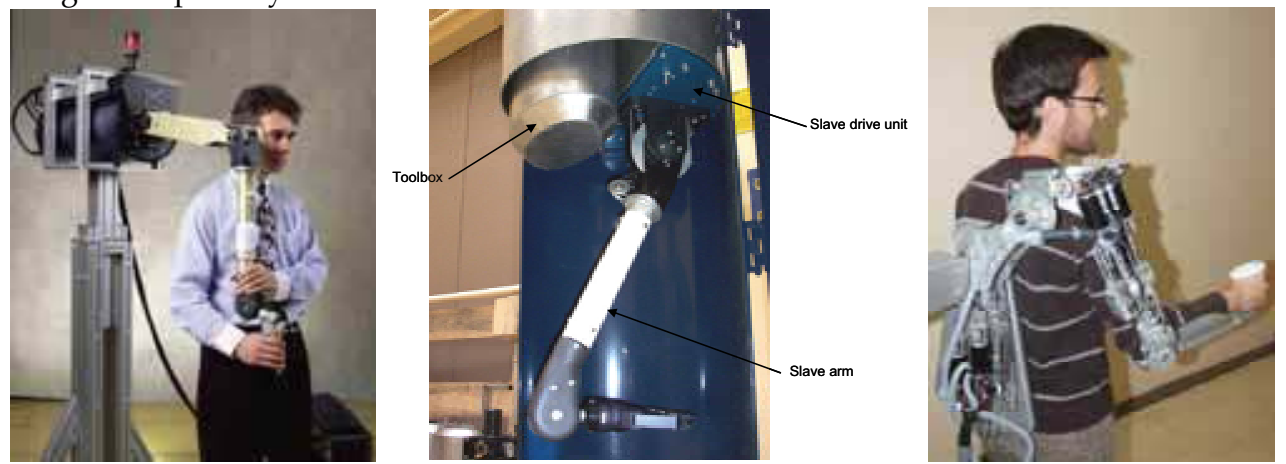

Fig. 1. Three chronological applications of the SCS actuator: Left, the master arm Virtuose ${ }^{\mathrm{TM}}$ 6D 40-40 (CEA/Haption) ; Center, the slave arm STeP ; Right, A 4 axis version of the ABLE, a upper limb exoskeleton (CEA) 
Its mechanical architecture also features several dedicated innovations - shoulder articulation, adjustable segments, forearm-wrist articulated cage - which all work in tight synergy with the actuators. Evaluation of this device for rehabilitation purpose is undergoing and future applications of the SCS actuators to low-limb exoskeletons and anthropomorphic assistive arms are also planned.

\section{Genesis of the SCS actuator}

\subsection{The problematic of linear torque amplification in Electrical Master Slave} Manipulator (EMSM)

The SCS actuator is originally a new answer to the problem of electrical motor torque amplification, a domain pioneered by electrical master-slave manipulators in which our laboratory has been tightly associated: (Goertz et al., 1955) ; (Galbiati et al., 1964) ; (Flatau, 1965) ; (Flatau \& Vertut, 1972) ; (Vertut et al., 1975) ; (Köhler, 1981) ; (Vertut \& Coiffet, 1984). In these types of manipulators, force feedback is simply obtained through mechanical reversibility and a high linearity of force transmission. The absence of torque/force sensor and associated drift and calibration procedure contribute to a high reliability of the machine. For example, the Mascot EMSM system used by Oxford Technologies Ltd under the name DEXTER has performed over 7,500hrs of remote handling tasks inside the JET (Joint European Torus, UK) with a system availability above $95 \%$ in tough conditions. However industrially proven machines, built under strict quality requirements, are expensive and rather bulky. Fig. 2 shows important pioneering machines each of them associated with their torque amplification solutions.
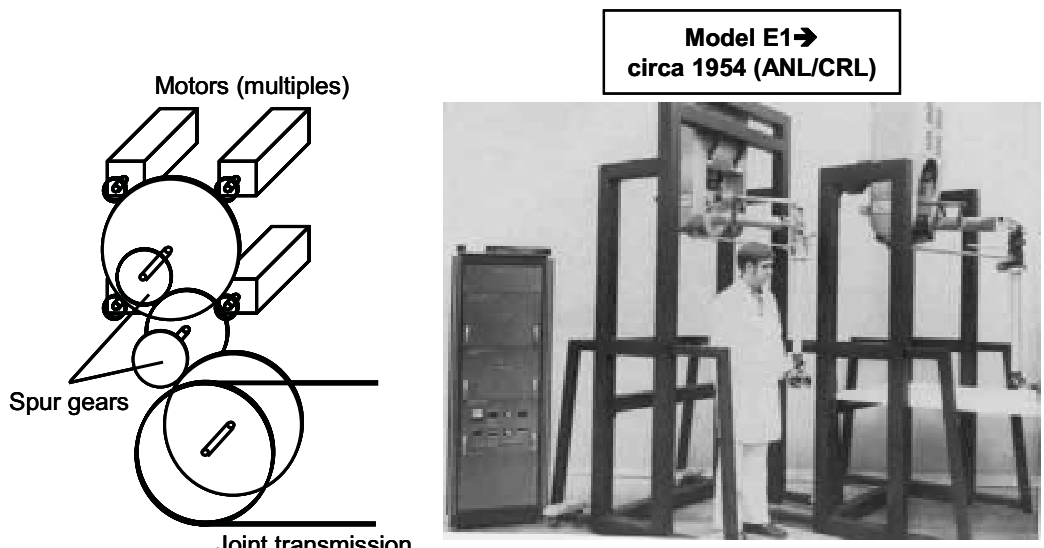

cable 


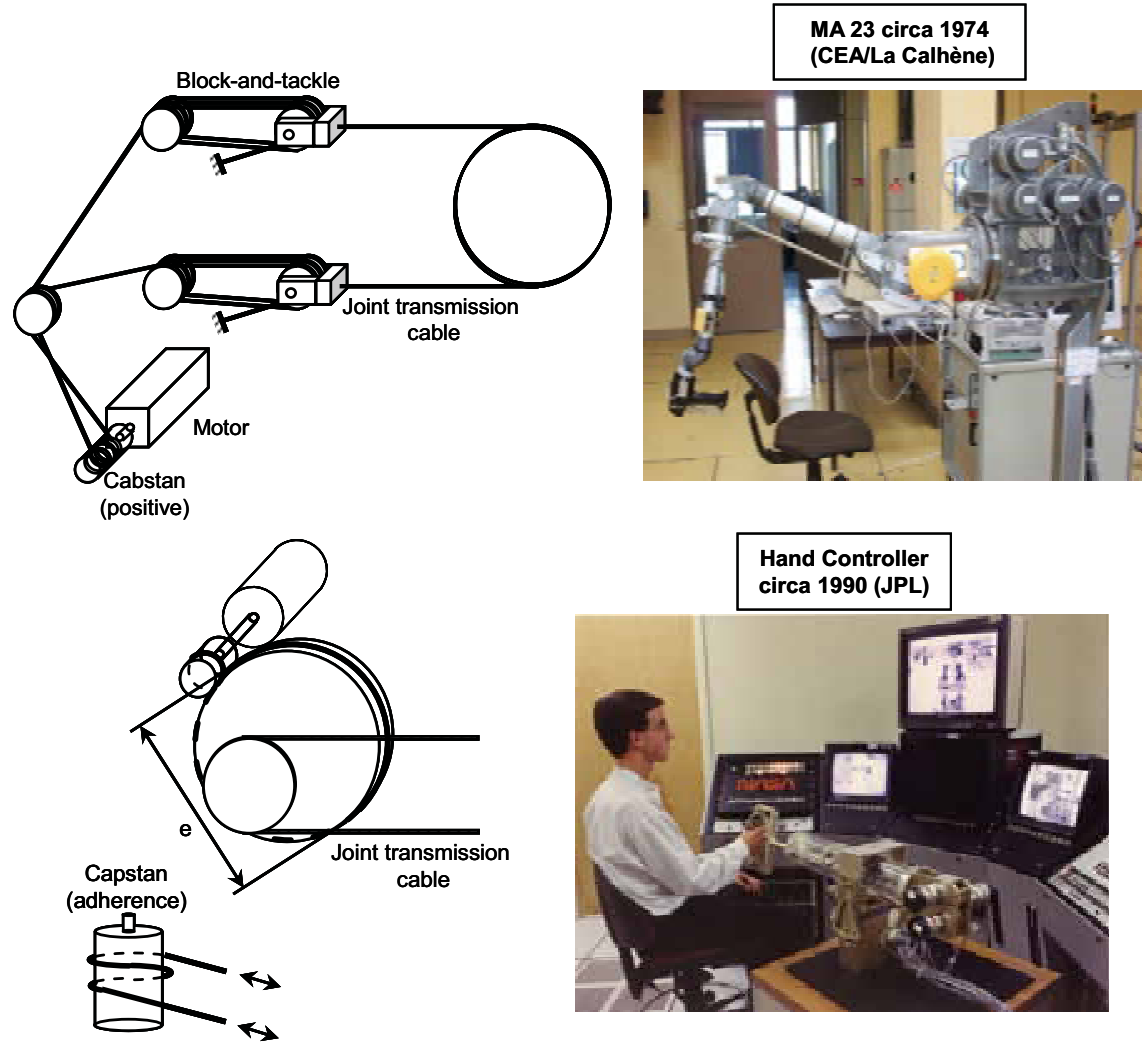

Fig. 2. Landmarks in torque amplification in electrical master-slave telemanipulator (EMSM)

The first principle has been used by R. Goertz on all his designs from the E1 model (the first servomanipulator) to the E4 and Model M. Motor torque is amplified using high-precision spur gears driving the joints either directly (translation joints) or, like the scheme shows, through transmission cable (for remote rotation joints). The second is due to J. Vertut and is team for the MA 23. Motor torque is amplified using block-and-tackle cable (or tape) arrangements which drives a transmission cable (or tape). The last one, the capstan has been used on the Hand Controller. The cable is wrapped around pulleys to increase the adherence, thus enabling the capstan to transmit more torque with very low tension in the cable resulting in a very low friction threshold. For this reason, this is today the more sensitive device for torque amplification and it is most commonly found on haptic devices.

\subsection{Force reflection and force transmission in a mechanical linkage}

Force reflection (or force feedback) can be defined as the force exerted by the operator on the master device to balance the force exerted by the load on the slave device. This force may be altered in intensity and sense depending on the properties (reversible/irreversible or selflocking) and performances of the mechanical transmission used (Fig. 3). 

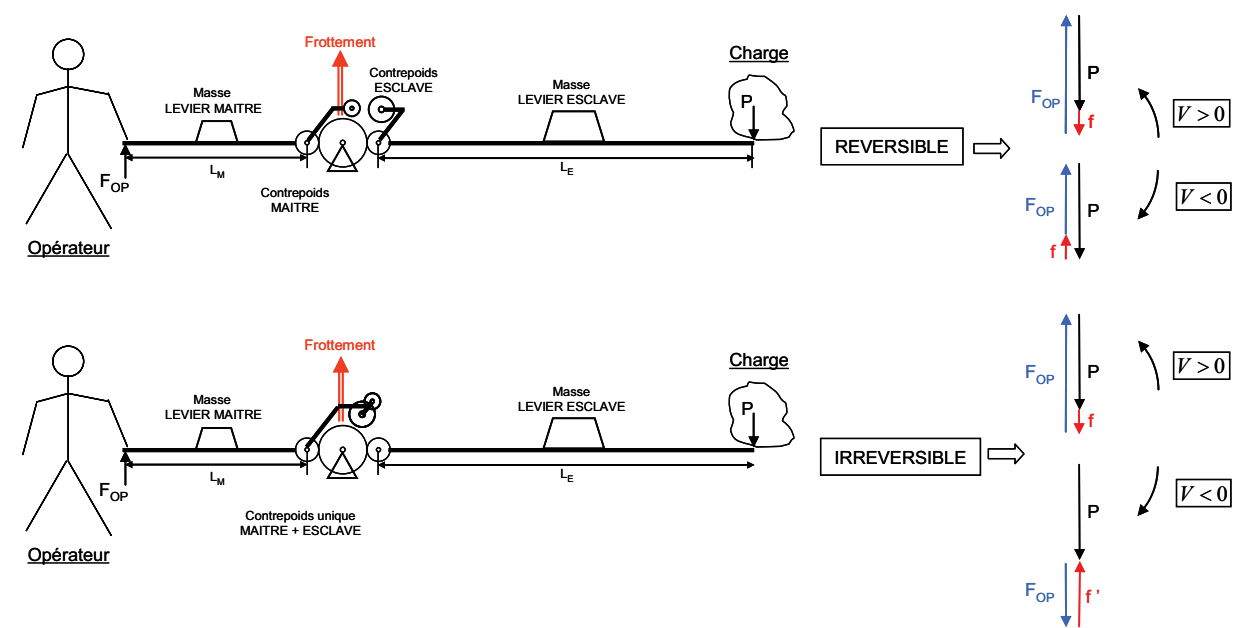

Fig. 3. The concept of force reflection and its alteration with mechanical transmission properties (Top: reversible; Bottom, irreversible)

We can see that irreversibility makes the force feedback incoherent and is thus always avoided in mechanical telemanipulation.

Reversible/Irreversible - Bilateral and Backdrivable

It should be noticed that a reversible transmission is always paired with a bilateral (or backdrivable) behaviour whereas an irreversible (self-locking) transmission may be given a bilateral behaviour through assistance in a closed loop mode with a force sensor. This is why it is useful to avoid confusion between the mechanical property of the transmission obtained by construction with its behaviour. Table 1 summarizes the various cases encountered.

\begin{tabular}{|c|c|c|}
\hline \multirow{2}{*}{$\begin{array}{c}\text { Mechanical type } \\
\text { (constructive property) }\end{array}$} & Non assisted (open loop) & Assisted (closed loop) \\
\cline { 2 - 3 } & Unilateral - Self-locking & Bilateral - Backdrivable \\
\hline Irreversible & \multicolumn{2}{|c|}{ Bilateral - Backdrivable } \\
\hline Reversible & \multicolumn{2}{|c|}{} \\
\hline
\end{tabular}

Table 1. Mechanical properties and behaviour of transmissions

Force transmission and force amplification diagram

It is possible to use a universal input-output force transmission diagram to represent the concept of force transmission and amplification for any kind of mechanism (Garrec, 2002). Fig. 4 is a simplified diagram of force transmission for a reversible transmission. Intersections $(\mathrm{I}, \mathrm{J})$ between characteristics are only fictive. 


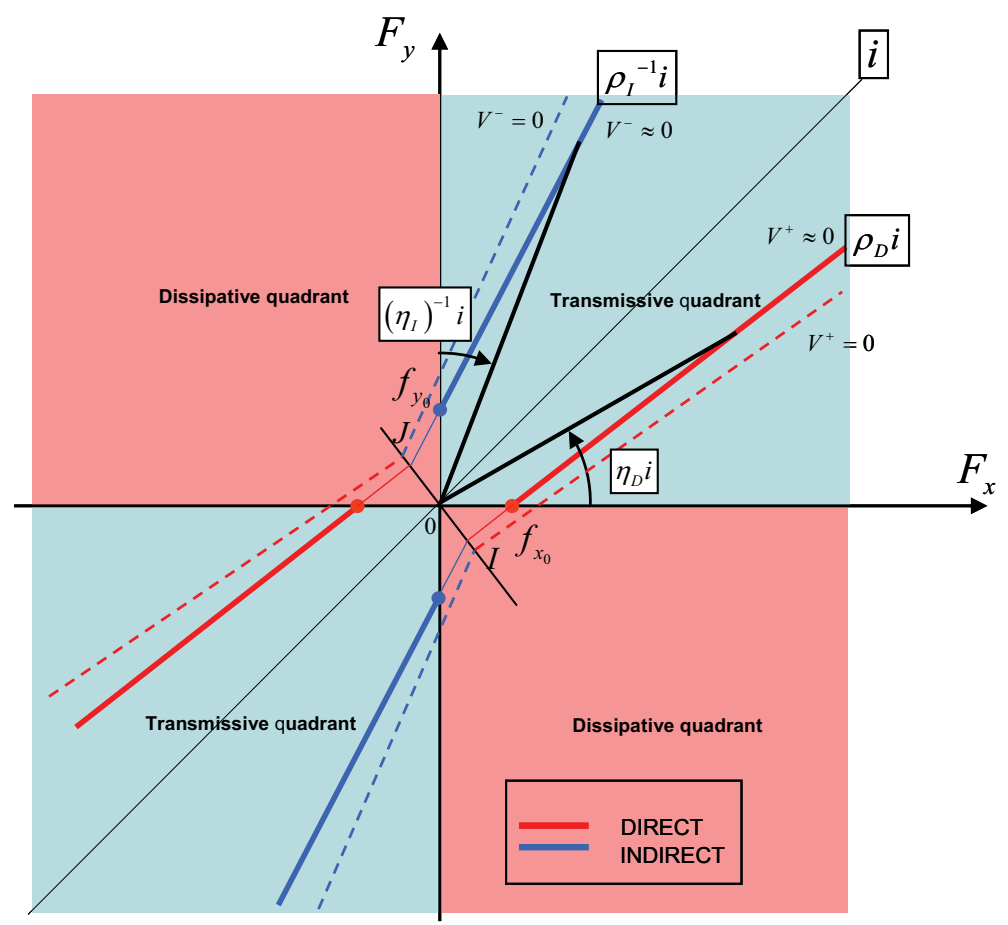

Fig. 4. Force transmission diagram for a reversible transmission

To discuss the basic performances of the transmission, it is sufficient to restrain the representation to the dry friction (Coulomb law). It can be shown that adding a viscous friction would only enlarge the bi-conical diagram. Since mechanical components may transform torque in force, input and output axis do not necessarily have the same unit, $F_{x}, F_{y}$ must be considered as generalized efforts. The reference characteristic (i coefficient) corresponds to the kinematic ratio, so in reference to the chosen coordinates, it represents a strictly linear amplification/conversion of forces/torques without friction. Dotted lines correspond to the static dry friction (no speed) and plain lines correspond to the kinematic dry friction (low speed). Red (DIRECT) and blue (INDIRECT) characteristics have the respective coefficients $\rho_{\mathrm{D}}$ and $\rho_{\mathrm{I}}$. For any mechanism comprising an incline (screw, worm gear, etc.), $\rho$ values are potentially different producing an asymmetry.

The minimum friction in the mechanism created by internal constraints, leads to minimum input and output friction (sometimes called no-load input/output friction or hysteresis). The transmissive quadrant (in blue) corresponds to a real transmission of energy between input/output or vice versa. In the dissipative quadrant (in pink), the mechanism is dissipating the energy supplied by both the input and the output.

In the transmissive quadrant, the efficiency $\eta=F_{y} / i F_{x}$, can be defined and plotted as a function as the input force in relative scale $F_{x} / F_{x_{\max }}$. It represents the effective output 
force available for a given input force, which can be interpreted as a default of transparency of the transmission. Efficiency is null for the minimum friction $f_{x_{0}} / F_{x_{\max }}$ and tends to $\rho$ for its maximum value $F_{x} / F_{x_{\max }}=1$.

The notional diagram Fig. 5 shows an example of the dramatical influence of the minimum friction on the output force (transmitted force) for $\rho=0,95$ and for $f_{x_{0}} / F_{x_{\max }}$ respectively equal to $2 \%$ and $10 \%$.

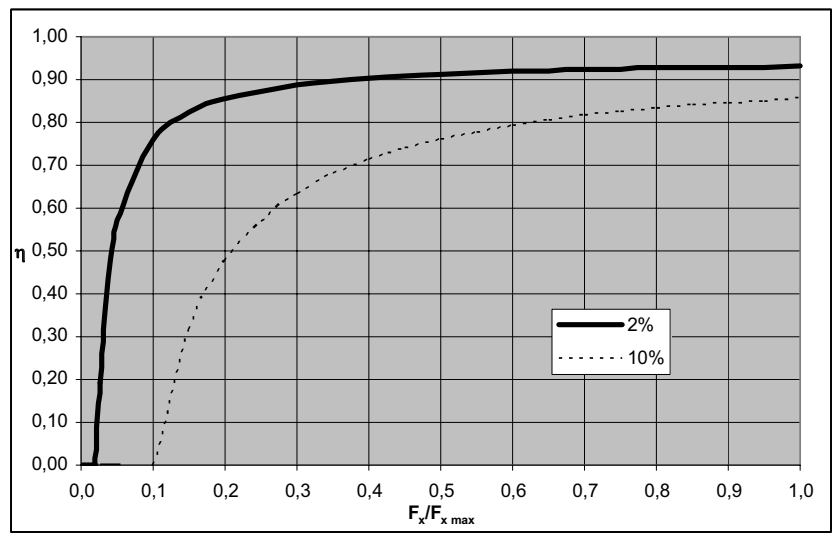

Fig. 5. Effect of relative friction on the availability of the efficiency

Note: For an irreversible mechanism $\rho_{\mathrm{I}}$ is negative and the corresponding characteristics are located in the dissipative quadrants (Fig. 6). In this case, $\rho_{\mathrm{I}}$ parameter is no longer an expression of an efficiency. 


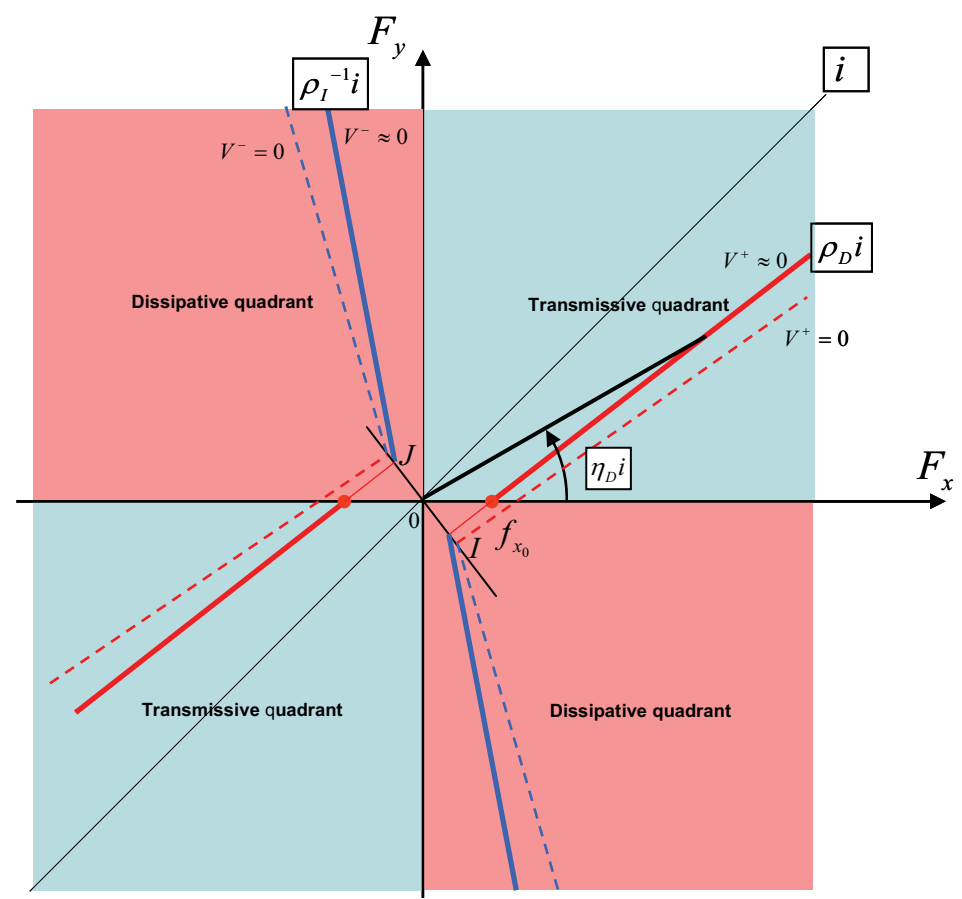

Fig. 6. Force transmission diagram of an irreversible transmission

\section{Linear force transmission}

We can now define the conditions to be fulfilled to obtain a linear force transmission:

- $\quad$ the mechanism must be reversible

- the minimum input-output friction must be minimized. A classical quantitative criteria has been proposed in the context of telemanipulator (Vertut \& Coiffet, 1984). It can be defined as the ratio of the minimum friction on the maximum capacity of the transmission (sometimes called relative friction). Its is a fundamental performance criterium in force reflecting manipulator

- $\quad$ the divergence of the characteristics must be minimum ( $\rho$ maximum)

- $\quad \rho_{\mathrm{D}}$ and $\rho_{\mathrm{I}}$ values should be ideally equal for symmetry purpose

\subsection{The Screw and Cable mechanics and its application to the master arm Virtuose 6D} In the late nineties our laboratory was trying to design a new teleoperation, force-feedback, master arm that would be less costly than the MA23 (CEA-La Calhène), a machine that has been consistently used in French teleoperation systems since its creation around 1974. This work resulted in the creation of the screw-and-sable transmission or SCS (Garrec, 2000) as well as the construction of a prototype of the master arm Virtuose 6D (Garrec et al., 2004). 
Mechanics of the Screw and Cable actuator SCS basic principles are presented in Fig. 7

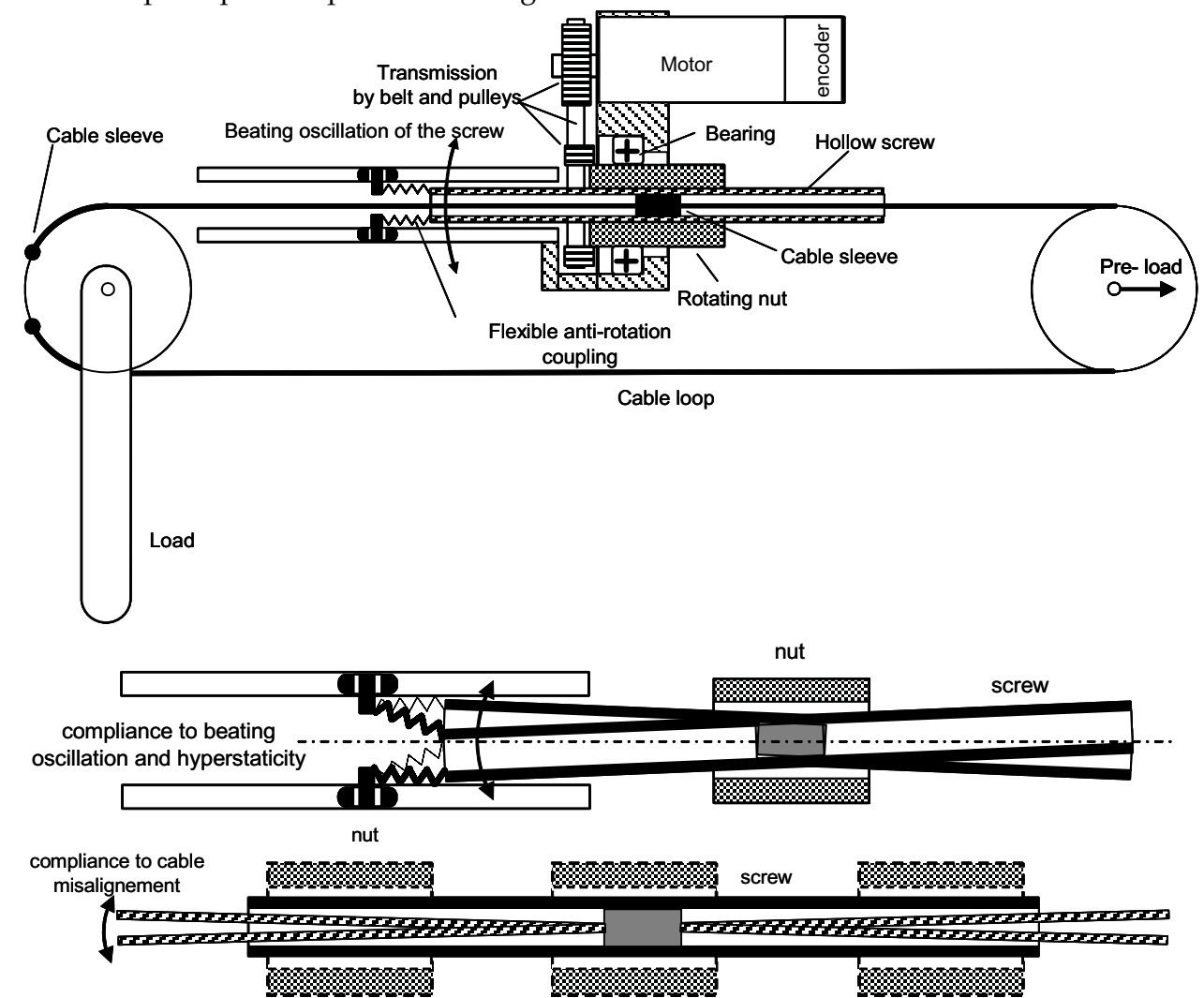

Fig. 7. SCS basic principles (patented)

A rotative joint is driven by a standard push-pull cable. On one side, the cable is driven by a ball-screw which translates directly in its nut without any linear guiding (the screw is locked in rotation thanks to rollers moving into slots). The nut rotates in a fixed bearing and is driven by the motor thanks to a belt transmission. Alternatively, pan-cake direct drive motors can be used (Fig. 13).

First of all, the ball-screw is free to oscillate thanks to a flexible coupling. These oscillations are known as beating oscillations and are amplified by the deliberate absence of centering device such as a linear bearing. Complementary the screw is bored and the cable passes inside with a radial play and is attached in its center. The scheme shows the various positions of the cable attachment relative to the nut when the screw is translated. This minimalist and compliant mounting almost completely isolates the screw from bending moments and thus guarantees a low and regular friction. The result is a highly linear force amplifier and transmitter which is also unusually compliant to manufacturing imperfections and structural deformations. 
Regarding the performance in torque amplification linearity, the Fig. 8 presents a torqueforce transmission diagram for a typical SCS using a THK BNK 1010 ball-screw (Diameter: 10mm ; Lead: $10 \mathrm{~mm}$ ). Both DIRECT and INDIRECT $(\rho)$ coefficient (maximum efficiency) are close to 0,94 and no-load friction represents approximately $1 / 1000$ of the maximum load capacity of the screw. These values show that in terms of force transmission quality and symmetry, a SCS competes with the best existing transmissions, the capstan excepted.
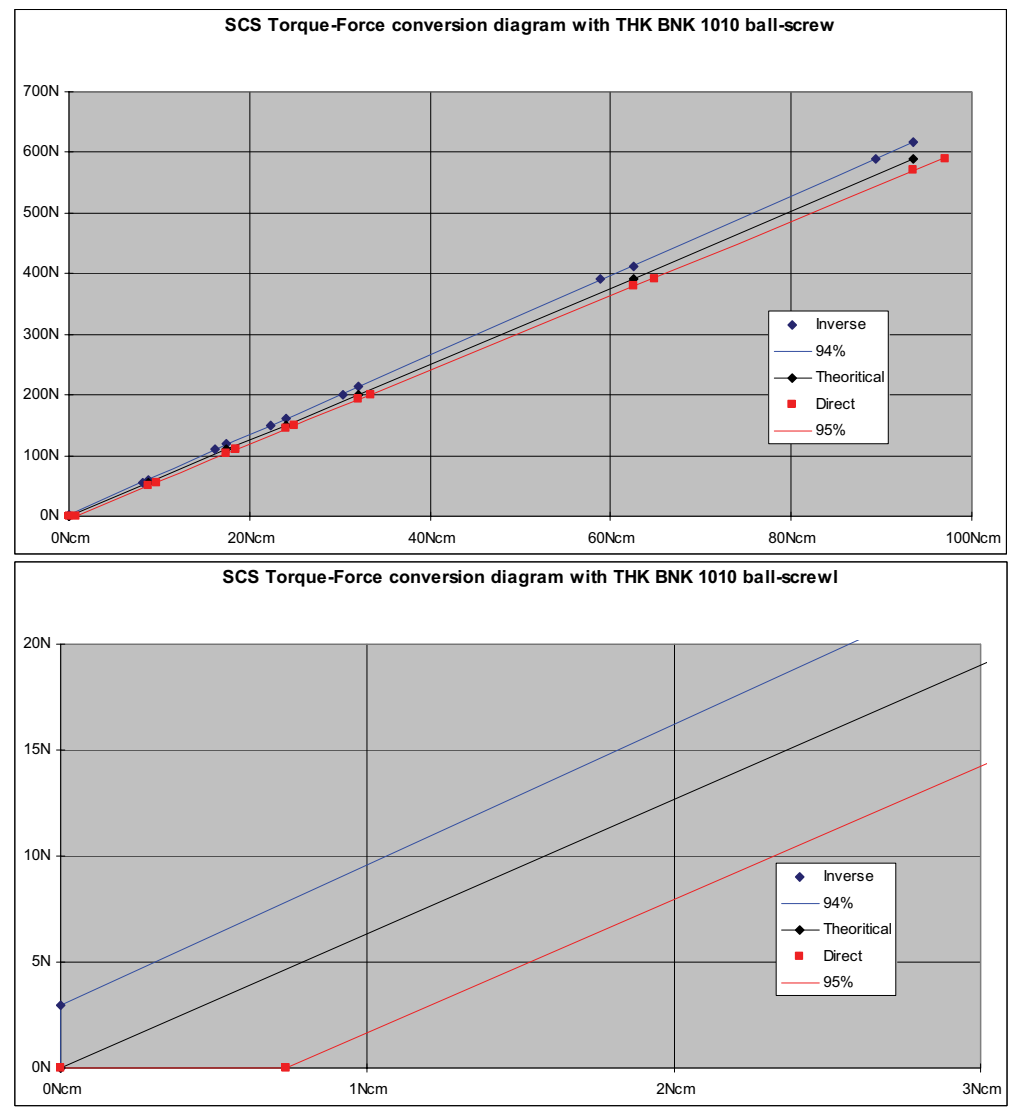

Fig. 8. A typical SCS force transmission diagram (in the transmissive quadrant): Top, default of linearity ; Bottom, a magnified view of the input/output friction thresholds

Filtering effect of the centered attachment of the cable

A simple modeling of the effect of cable tension on the efforts created between the screw and the nut demonstrate the efficiency of the centered attachment in comparison with a conventional attachment at the extremities of the screw. In the example Fig. 9, the travel of the screw is $+/-100 \mathrm{~mm}$. Both the bending moment and transversal force created by the cable are reduced about 10 times (on this example) in comparison with a standard attachment at the extremities of the screw. This important result explains, in the existing 
realizations, the suppression of any detectable friction irregularities, even for strokes up to $200 \mathrm{~mm}$.
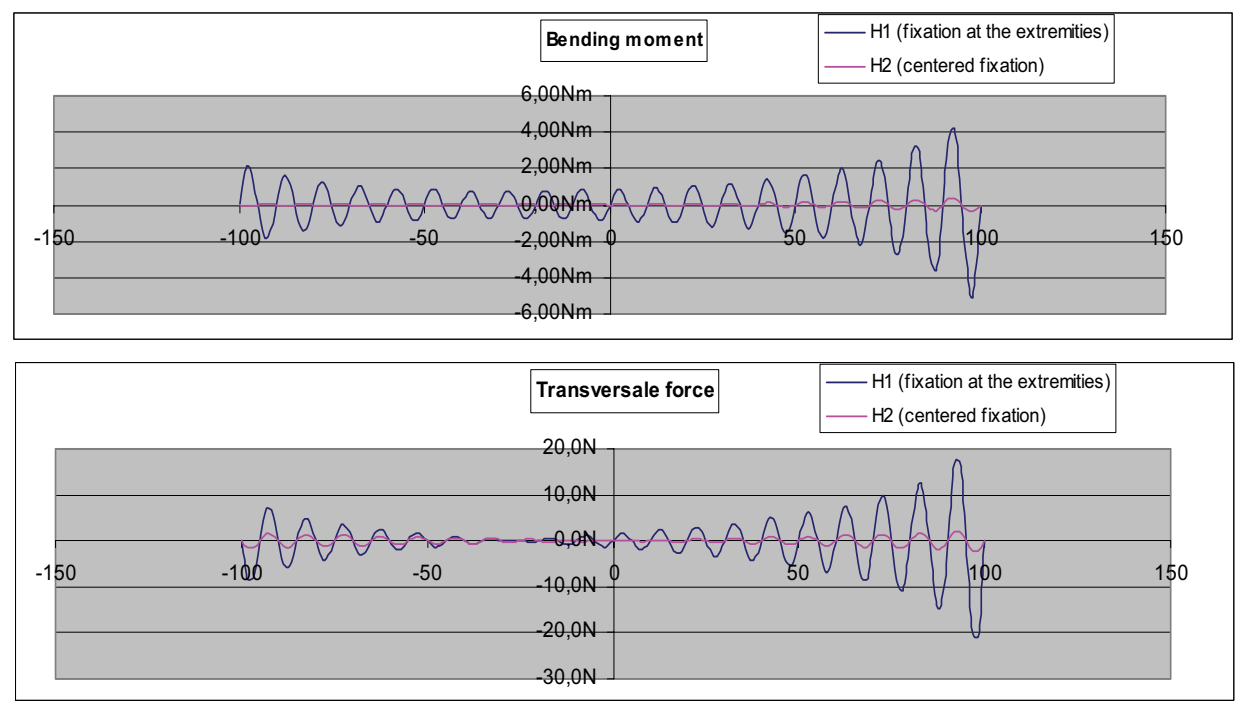

Fig. 9. Typical filtering effect of the centered attachment of the cable

The master arm Virtuose ${ }^{\mathrm{TM}}$ 6D 40-40

The first prototype has been presented during the 9th American Nuclear Society Topical Meeting on Robotics and Remote Systems congress in Seattle in 2001 and is today manufactured by Haption ${ }^{\circledR}$ under the name Virtuose ${ }^{\mathrm{TM}}$ 6D 40-40. It is the combination of an articulated arm issued from an existing mechanical telemanipulator, the MA 30 (La Calhène) and a motorization unit packing 6 SCS actuators at the base of the arm (Fig. 10).

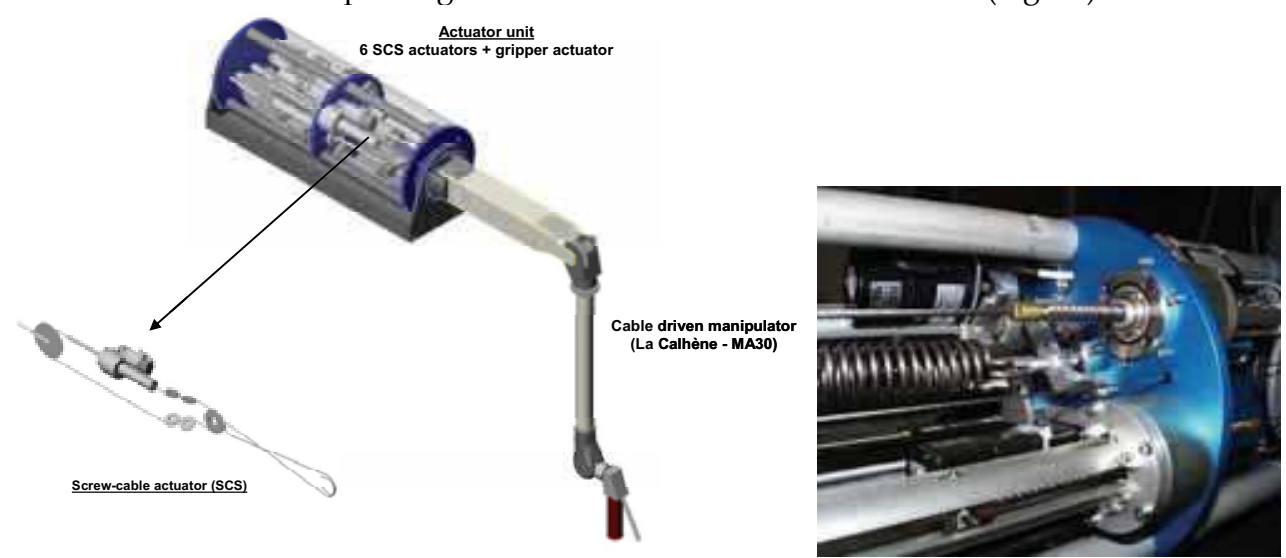

Fig. 10. Virtuose 6D: the first 6 axis force feedback master arm powered by 6 screws and cables 
Gravity compensation is realized by computed torques provided by the motors, excepted on the first axis where a spring maintains the first limb around the horizontal at rest.

The following pictures shows the industrial version, Virtuose ${ }^{\mathrm{TM}} 6 \mathrm{D} 40-40$, used in the thruthe-wall telescopic teleoperator MT 200 TAO developed for the needs of AREVA's reprocessing plant hot-cells (Garrec et al. 2007).

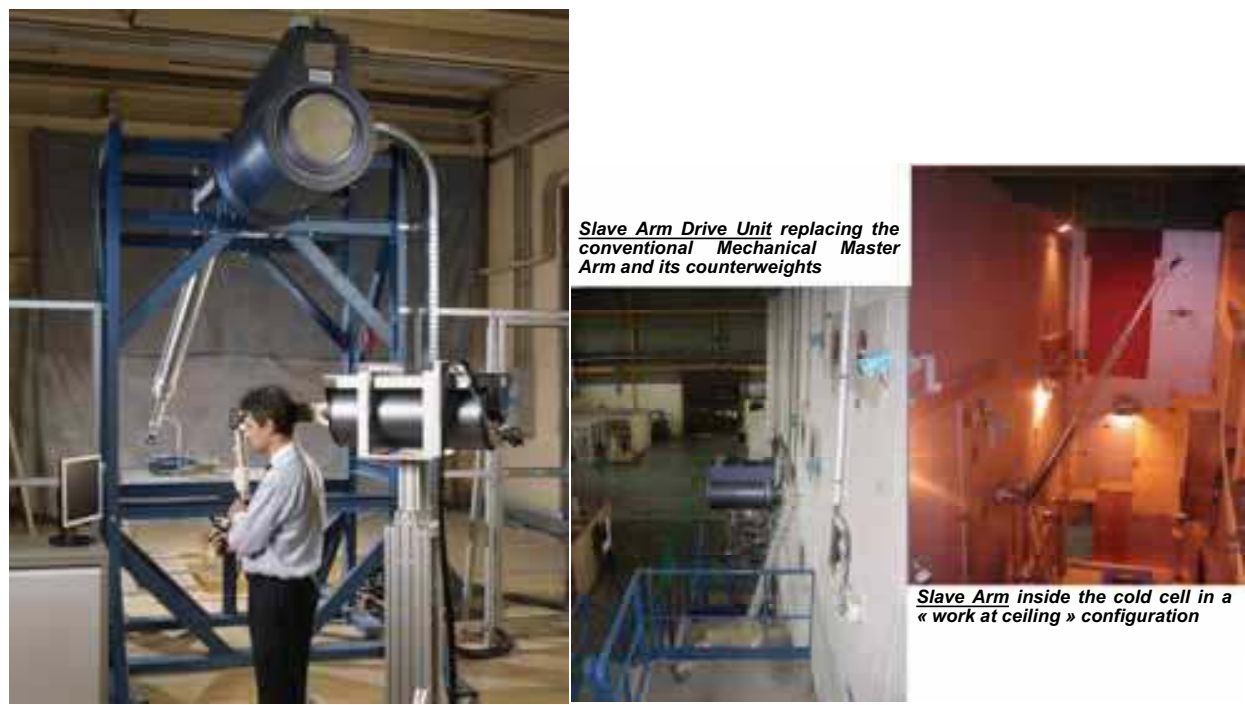

Fig. 11. The MT 200 TAO (CEA/AREVA) developed for AREVA La Hague hot-cells.

The following table summarizes the main specifications of the prototype equipped with brushless DC motors.

\begin{tabular}{|c|c|}
\hline DoF & 6 \\
\hline Cartesian working volume & $400 \mathrm{~mm}^{\prime} 400 \mathrm{~mm}^{\prime} 400 \mathrm{~mm}$ \\
\hline Continous force & $40 \mathrm{~N}$ \\
\hline Continuous moment & $2 \mathrm{Nm}$ \\
\hline $\begin{array}{c}\text { Theorical resolution in translation } \\
\text { (12 bit) }\end{array}$ & $0,02 \mathrm{~mm}$ \\
\hline $\begin{array}{c}\text { Theorical resolution in rotation (12 } \\
\text { bit) }\end{array}$ & 0,1 milliradian \\
\hline Dry friction (translation) & 2 to 3 N \\
\hline Total mass of the arm & $35 \mathrm{~kg}$ \\
\hline
\end{tabular}

Table 2. Virtuose 6D prototype main specifications

\subsection{The STeP teleoperation system}

Shortly after completing Virtuose 6D, a custom designed slave arm based on the same philosophy was design for the need of the teleoperation system STeP (STeP: Système de Téléopération en Puits) dedicated to retrieve radioactive material in a well (Fig. 12). The specifications of this system have been previously presented (Goubot \& Garrec, 2003). 


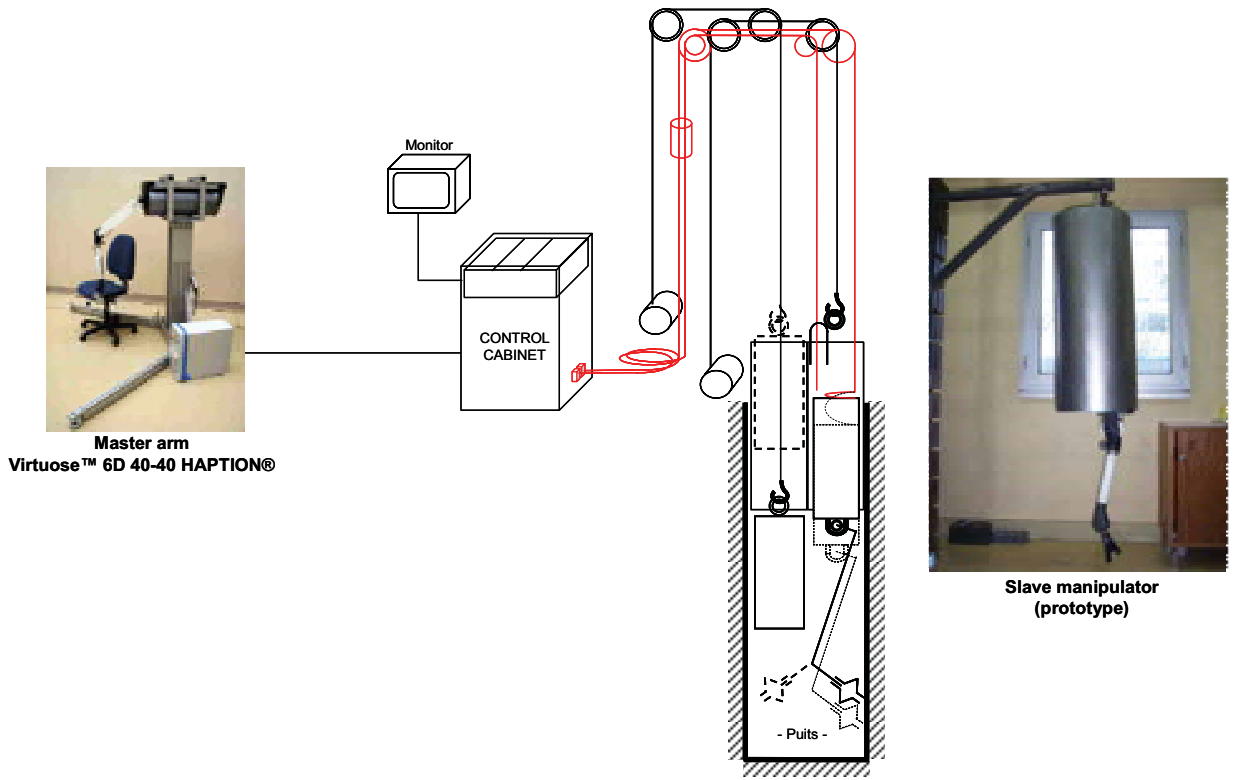

Fig. 12. A general view of the STeP teleoperation system for interventions in well

The slave arm is designed to work in a radioactive environment and it occupies only the half well's section. A tool box travels in the left space to bring tools and retrieve material. It is a simplified 5 axis arm equipped with a gripper, the first movement being a vertical translation. All joints are driven by cables and are provided with force feedback. We expanded upon the same SCS mechanics but this time we opted for direct-drive concentric pan-cake motors in order to pack its 6 actuators inside a half-cylinder housing which also integrates counterweights to compensate the actuator unit's weight on its vertical travel (Fig. 13). 


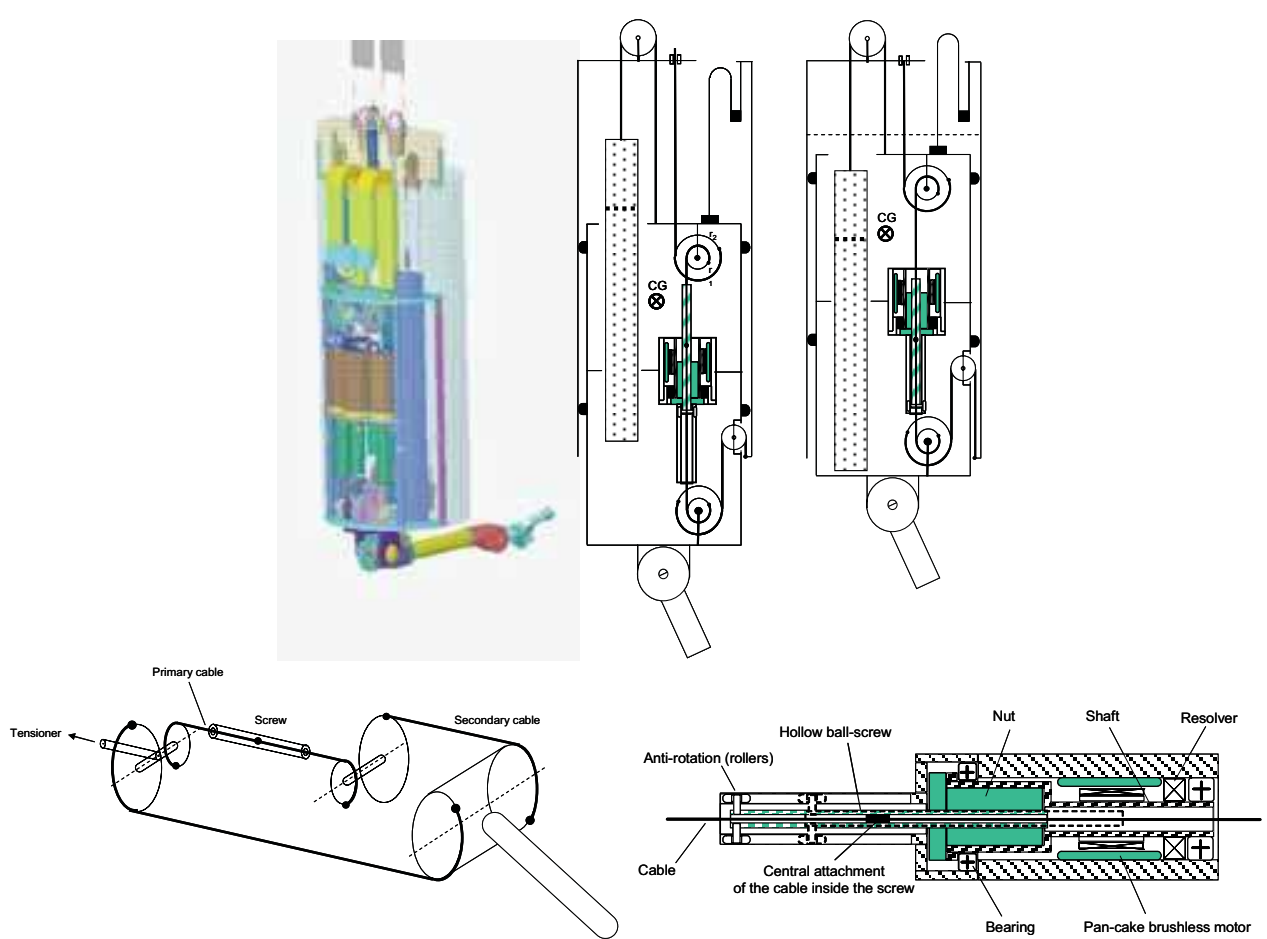

Fig. 13. Top, slave unit and a detail of its typical balanced translation motion ; Bottom, special type of loop used to increase linear travel and a SCS driven by concentric pan-cake motors

In comparison with master arms, slave arms have greater joint amplitude. This is why we had to slightly increase the complexity of cable loops to increase the linear displacement of the cable and thus stay within the allowed longitudinal dimension of the unit. Here again, the SCS actuators contribute to an extremely compact motor unit.

\subsection{The new trade-off offered by SCS}

All of the previous solutions - spur gears, block-and-tackle, capstan - have the common drawback of a transversal motor compared to the direction of cables. The SCS on the contrary is the only one where the motor is parallel to the cable and this enables a transversal joint to be driven without minimal losses, avoiding bevel gear. In addition to the well-known advantages of cable transmissions (shock absorption, smoothness, high efficiency, and design versatility for intricate routings through joints) the basic advantages of the SCS are:

- $\quad$ high force capacity (with ball-screws for instance)

- high linearity in force amplification allow force control without force sensor (reliability, absence of drift and calibration procedure, electromagnetic immunity, simplified wiring) 
- motor aligned parallel to cable: compact arrangement to actuate transversal without beveled gearboxes

- $\quad$ low inertia (with appropriate lead)

- $\quad$ high linear stiffness

- highly tolerant to manufacturing incertitude and to structure flexibility (wide choice of structural material)

- $\quad$ cable endurance (large cable section and low speed)

Regarding drawbacks in comparison with other tendon driven mechanism, the SCS presents a potential asymmetry in terms of stiffness, as soon as one of the cable portion looses its tension.

\section{The design of the upper limb exoskeleton ABLE 4 axis}

In the first applications of the SCS the advantage of the alignment of the motor with the cable benefited to the compactness of the actuator based unit. We realized that it was possible to go further by integrating the SCS in the moving parts of the arm which would reduce the length of the cable and simplify its routing. Correlatively, in order to limit the detrimental effect of the increased moving mass (both in terms of gravity torque and inertia) we chose to reposition the dead mass of motor near the upstream articulation of the arm using lightweight shafts to transmit the torque. This is actually the application to the SCS of a known idea (Flatau \& Vertut, 1972). Altogether this combination represented a new tradeoff (Fig. 14).

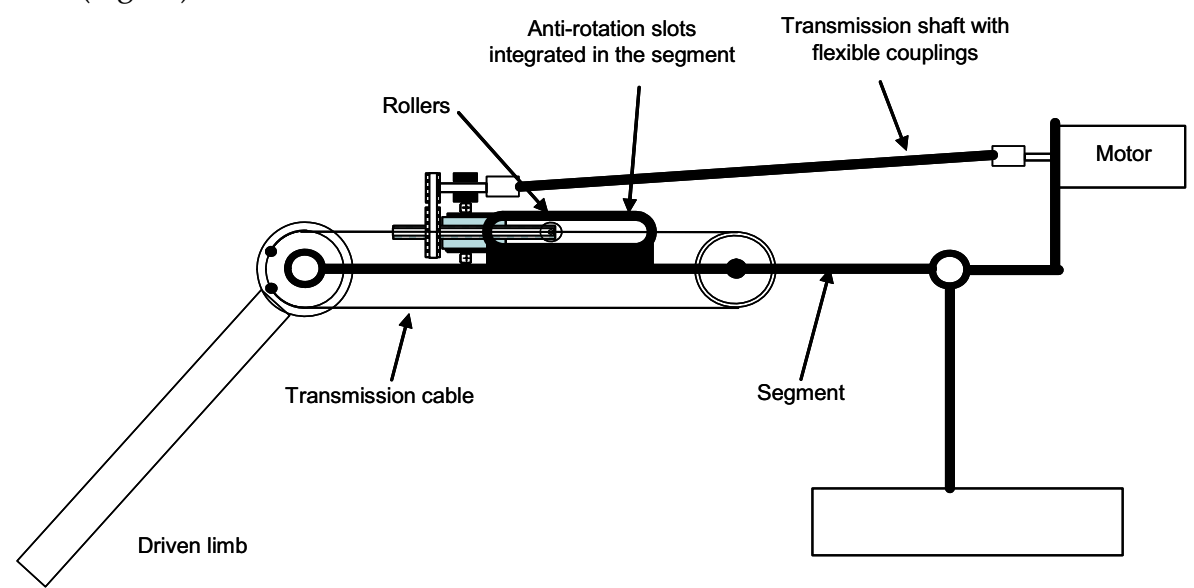

Fig. 14. Embedded SCS principle

The design of an upper limb exoskeleton appeared then as an appropriate application of this principle paired with an exciting design challenge.

The second option was to take advantage of the flexibility of the cable to pack two SCS's in the arm module, each of them actuating a transversal axis (shoulder and elbow joint). The overall result is a streamline arm module where the two SCS's perform alike artificial electrical muscles (Fig. 15). 


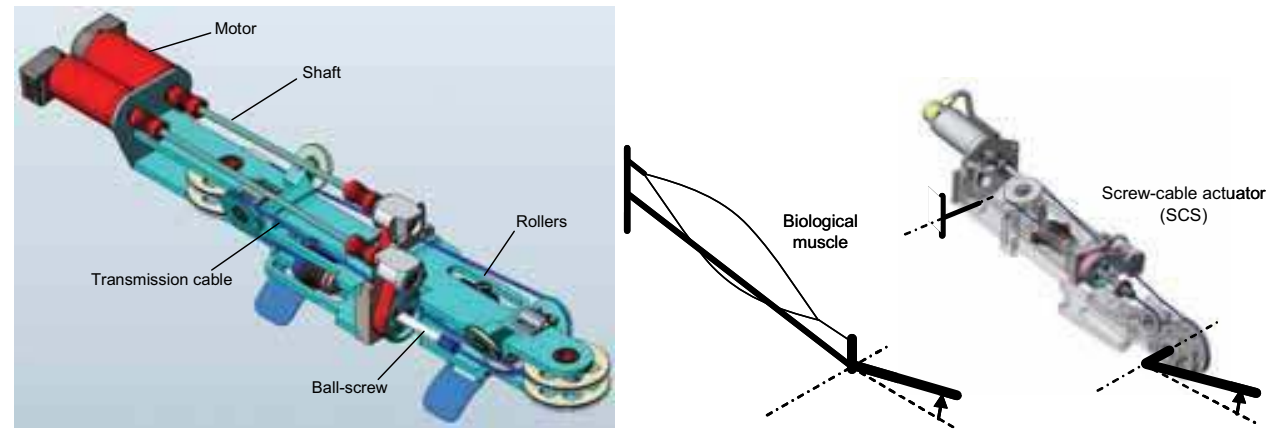

Fig. 15. Arm module twin actuators and its analogy with biological muscles

In a second phase we designed the shoulder joint and the back module. The scheme Fig. 16 shows the resulting kinematics of the 4 first joints. The shoulder articulation is a spherical articulation made of three orthogonal pivots whose common intersection approximately coincides with the center of the person's shoulder.

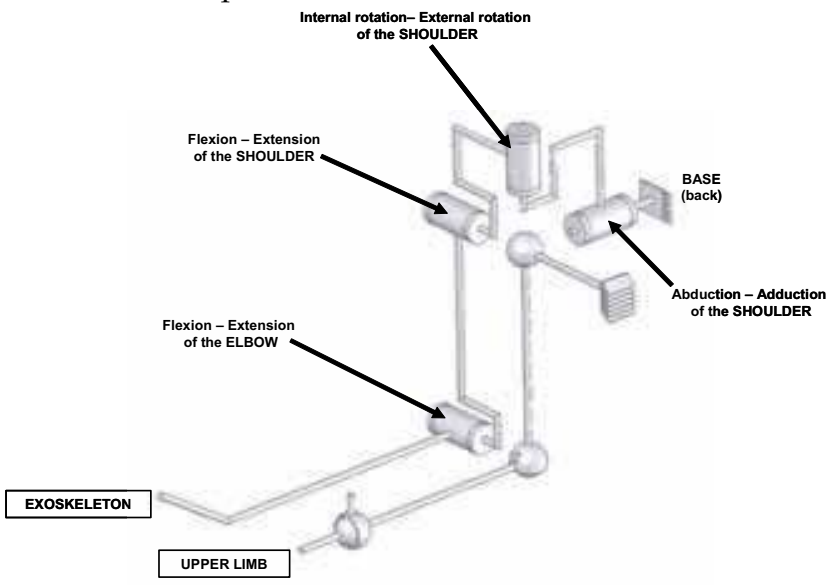

Fig. 16. ABLE - 4 axis kinematics

However, the major difference with previous designs is that the second joint is realized with a circular guide. Such an arrangement is both free of singularity and not invasive as shown on Fig. 17.

The back module incorporates two SCS which drive the first and second joints whereas the third joint is driven transversally by one of the two embedded SCS of the arm module (Fig. 18). The coupling effect between the two first joints is classically compensated by the control. 
Fig. 17. ABLE - 4 axis shoulder kinematics
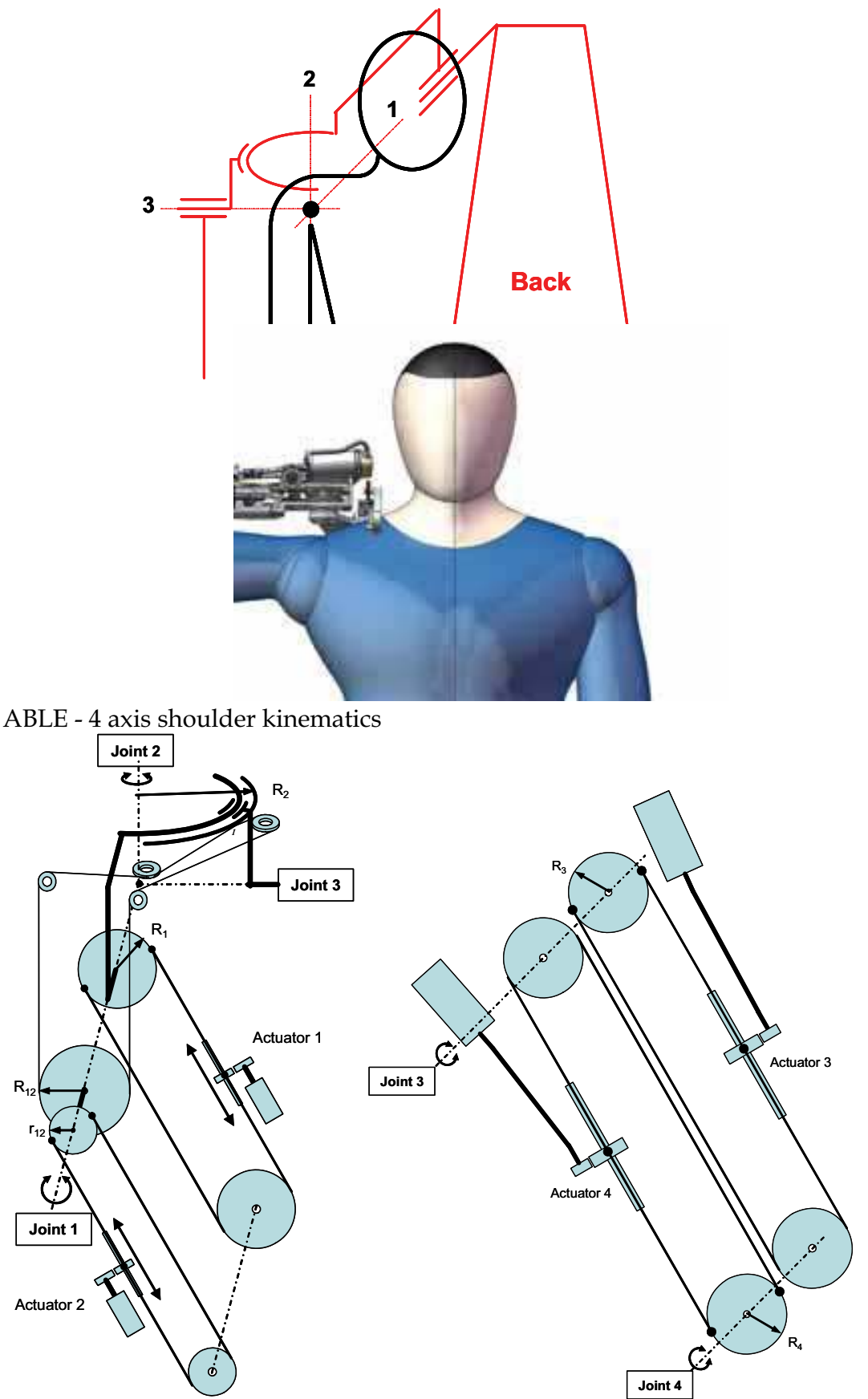

Fig. 18. ABLE - 4 axis actuator kinematics: left, back module (Joints 1\&2) ; right, arm module (Joints 3\&4) 
The result is a simple, integrated and morphologically compatible design combined with a distributed actuator mass and volume along the structure (Fig. 19). The ABLE 4 axis general architecture and design was previously presented in (Garrec et al. 2004) ; (Garrec et al. 2006); Garrec et al. 2008)

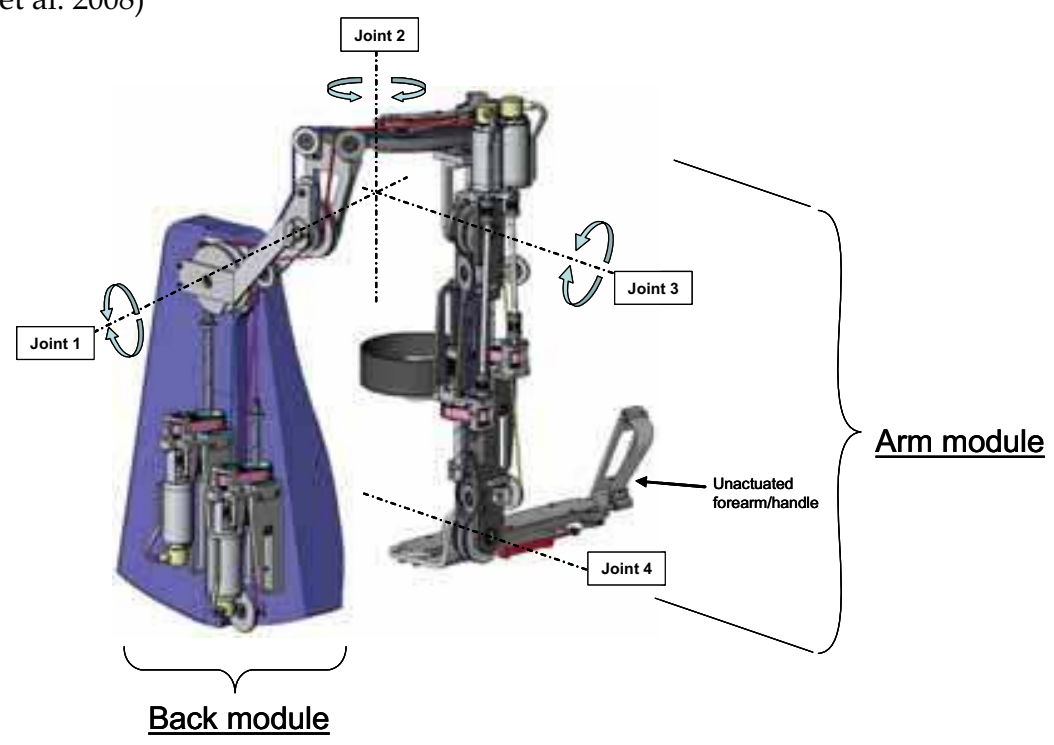

Fig. 19. ABLE - 4 axis architecture

It is important to note that since the two SCS only occupy the half of the back module, it is possible to integrate the motorization of a second exoskeleton without any change of its volume. The Table 3 summarizes the main specifications of ABLE - 4 axis.

\begin{tabular}{|c|c|c|c|c|}
\hline MODULE & \multicolumn{2}{|c|}{ BACK } & \multicolumn{2}{|c|}{ ARM } \\
\hline \multirow{2}{*}{ JOINT } & Axis 1 & Axis 2 & Axis 3 & Axis 4 \\
\hline & Abduction / Adduction & Rotation Internal / External & Flexion/Extension & Flexion/Extension \\
\hline ARTICULATION & \multicolumn{3}{|c|}{ SHOULDER } & ELBOW \\
\hline Amplitude & & $110^{\circ}$ & & $130^{\circ}$ \\
\hline Motors & \multicolumn{4}{|c|}{ DC ironless Faulhaber type } \\
\hline Transmission & \multicolumn{4}{|c|}{ Belt + Ball-screw and cable (SCS) } \\
\hline Ratio & 106 & 107 & 71 & 71 \\
\hline Max. velocity in hand (approx.) & \multicolumn{4}{|c|}{$1 \mathrm{~m} / \mathrm{s}$} \\
\hline Joint torque (continuous) & $18 \mathrm{Nm}$ & $18 \mathrm{Nm}$ & $13 \mathrm{Nm}$ & $13 \mathrm{Nm}$ \\
\hline Continuous effort in hand (approx.) & $50 \mathrm{~N}$ & $50 \mathrm{~N}$ & $40 \mathrm{~N}$ & $40 \mathrm{~N}$ \\
\hline No-load friction in hand (approx.) & \multicolumn{2}{|c|}{$3 \mathrm{~N}$} & \multicolumn{2}{|c|}{$2 \mathrm{~N}$} \\
\hline
\end{tabular}

Table 3. ABLE 4 axis main specifications

\section{Toward ABLE 7 axis: the design of an innovative forearm-wrist module actuated by} SCS

Looking for completing ABLE with a forearm and wrist that would preserve its general design options, we realized that existing structures described in previous literature 
(Bergamasco et al., 1994) ; (Gupta \& Malley, 2006) ; (Frisoli et al., 2007) ; (Perry et al., 2007) did not address simultaneously the following requirements:

- $\quad$ open structure (for safety reason and psychological acceptance)

- lightweight

- low friction

- $\quad$ low inertia

- $\quad$ streamline

- scalable

We decided then to focus on the forearm design only, looking for a structure that would allow a sufficient axial rotation (prono-supination) and address the listed requirements.

\subsection{Forearm}

Parallel articulated structure (prono-supination)

In its basic version, the forearm mechanism is presented in Fig. 20. It combines a parallel structure made of 3 rods, connecting a mobile arch to a fixed arch thanks to ball-joints, and a fixed cantilever mast attached to the fixed arch, which extremity supports a bearing made of 3 rollers which determine the mobile arch to rotate around its center. The mechanism is altogether acting as a forearm structure and a circular guiding for the axial rotation (pronosupination). Incidentally, this movement evokes those of radius-ulna bones. We can notice that more rods could be arranged in parallel without changing the proprieties of the structure, for example to increase the resistance or stiffness. In this case inner constraints would necessary appear (hyperstaticity) and should be limited by a suitable accuracy of the realization. Shear forces are balanced by the fixed cantilever mast whereas bending moments are balanced by traction/compression forces in the rods. This decomposition of the static torsor makes an optimal use of each element: miniature bearings can easily sustain the desired shear forces (about $50 \mathrm{~N}$ ) whereas lightweight rods/ball-joints can easily transmit the necessary traction/compression forces (about $150 \mathrm{~N}$ ). Compared to an existing industrial product such as THK HCR circular bearing or previous published designs, this mechanism presents a better compromise between volume, weight and friction and it can be easily scaled to different person sizes.

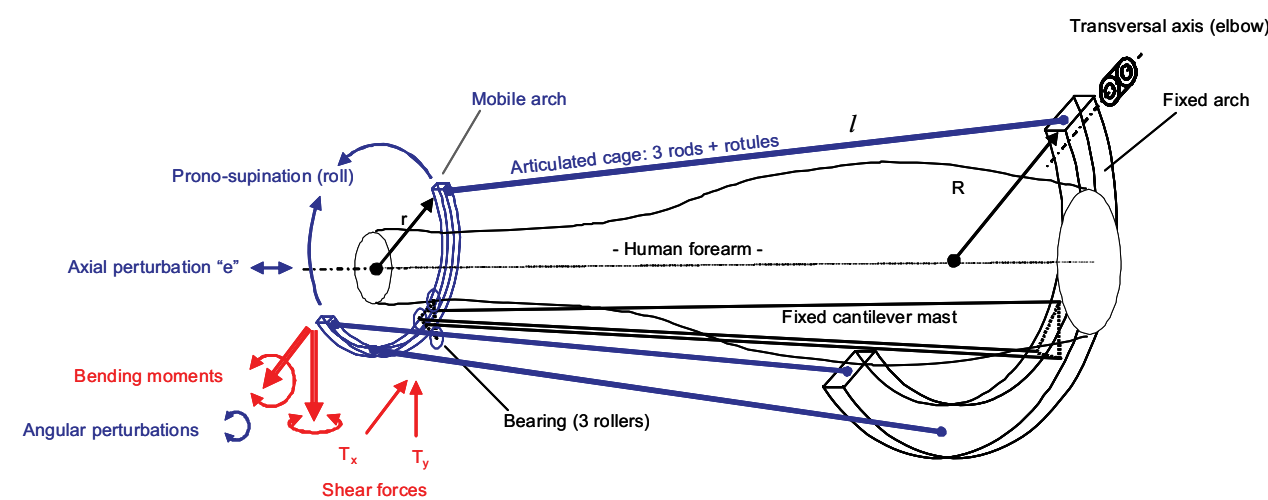

Fig. 20. Forearm parallel mechanism allowing an axial rotation concentrically to the human forearm (prono-supination) 
However, the amplitude of the rotation is naturally limited by interferences between rods and fixed parts but also because an axial translation of the mobile arch (Fig. 21) occurs when it rotates (non linear coupled motion).
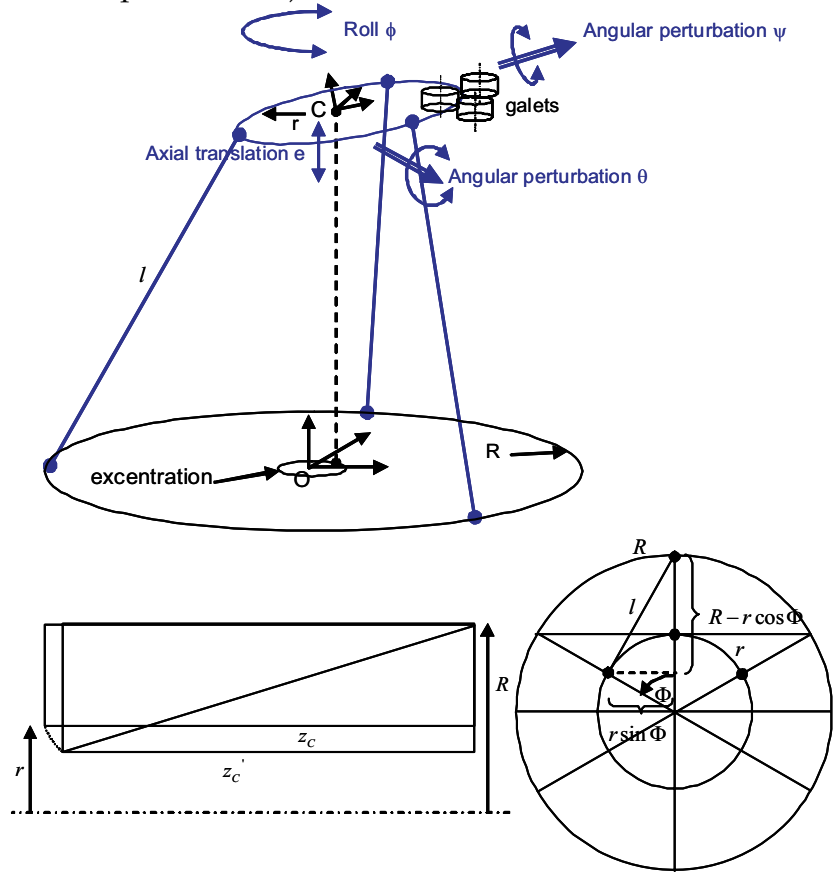

Fig. 21. Kinematic perturbations of the parallel mechanism

The expression of the perturbative translation is given by the equation (1).

$$
e=z_{c}-z_{c}^{\prime}=z_{c}\left(1-\sqrt{1+\frac{2 R r(\cos \Phi-1)}{z_{c}{ }^{2}}}\right) \text { (1) }
$$

An order of magnitude of the perturbative translation is given for an average-size human forearm in Table 4.

\begin{tabular}{|c|c|c|}
\hline Prono-supination amplitude & $\angle L$ & $120^{\circ}$ \\
\hline & $\angle$ & $60^{\circ}$ \\
\hline Fixed arch radius & $\mathrm{R}$ & $65 \mathrm{~mm}$ \\
\hline Mobile arch radius & $\mathrm{r}$ & $45 \mathrm{~mm}$ \\
\hline Nominal distance between arches & $\mathrm{z}_{\mathrm{c}}$ & $250 \mathrm{~m}$ \\
\hline Rod length & 1 & $251 \mathrm{~mm}$ \\
\hline Minimum distance between arches & $\mathrm{z}_{\mathrm{c}}^{\prime}$ & $244 \mathrm{mn}$ \\
\hline Maximum translation & $\mathrm{e}$ & $6 \mathrm{~mm}$ \\
\hline
\end{tabular}

Table 4. Estimated translation for a human forearm

We notice that in comparison with the flexibility of the skin and muscle, this perturbation $(\approx$ $2 \%$ ) is relatively small and thus likely to not be felt by the user. A second cause of 
perturbation is the offset of the center $\mathrm{C}$ of the mobile arch (fabrication incertitude, play or elastic deformation under the load) which will induce an oscillation of its plane. In our current design (Fig. 23), its amplitude is estimated to be kept below $1^{\circ}$ which should be again undetectable.

\section{Axial rotation drive}

The perturbative translation of the arch is obviously a major constraint for the design of the drive. Here again the SCS actuator brings an appreciable tolerance and the torque amplification offered by the screw and the belt is sufficient to avoid any complementary gear. The transmission cable has a particular routing through the fixed mast (Fig. 22).

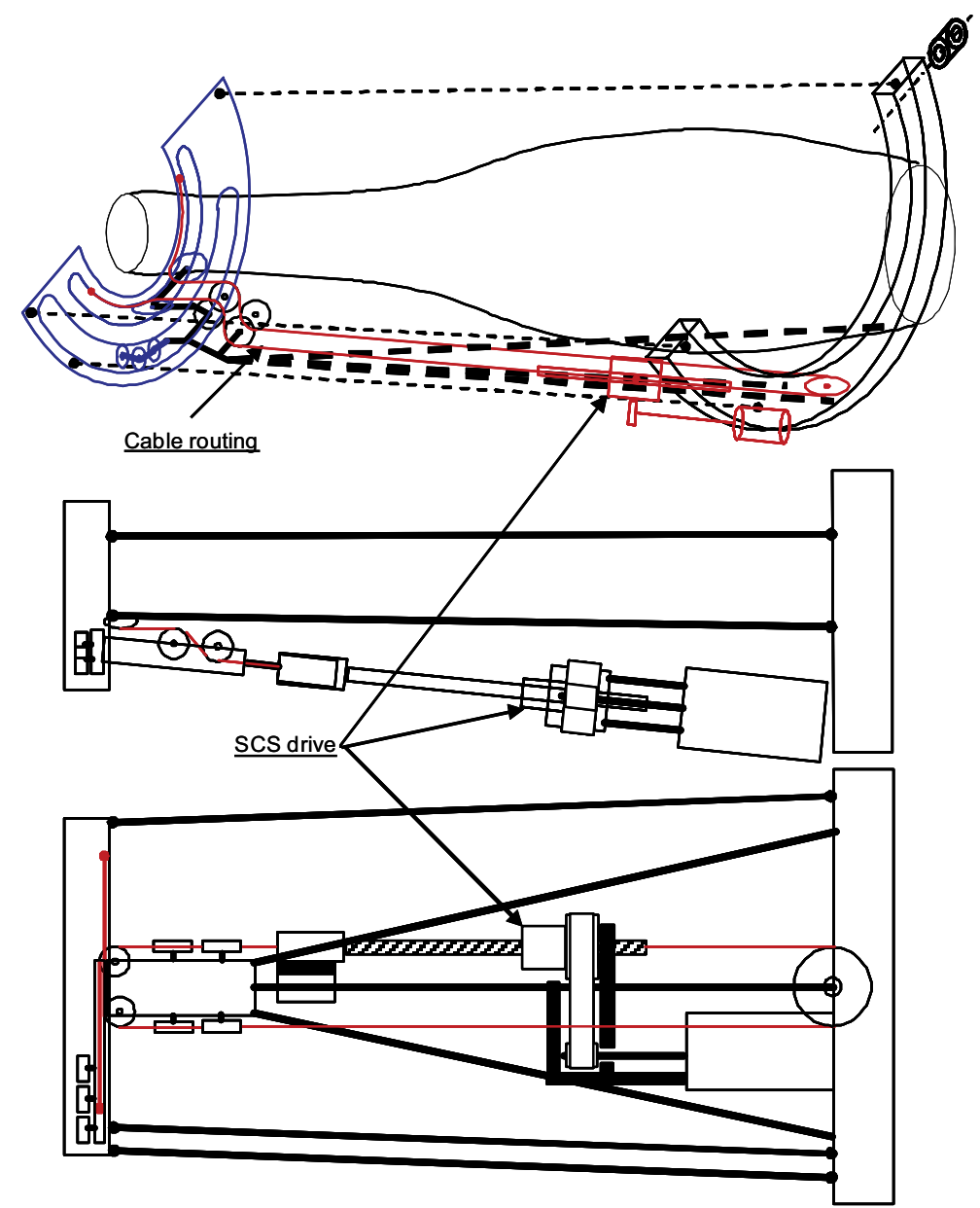

Fig. 22. Axial rotation drive by an SCS showing the cable transmission routing

The specific design of the SCS enables its integration within the mast overall volume. The combined rotation-translation movement of the arch creates a non conventional trajectory 
that requires a careful design of the grooves to limit cable length variations. Adjustments are also provided both in length and laterally. Fig. 23 shows a view of a current project.

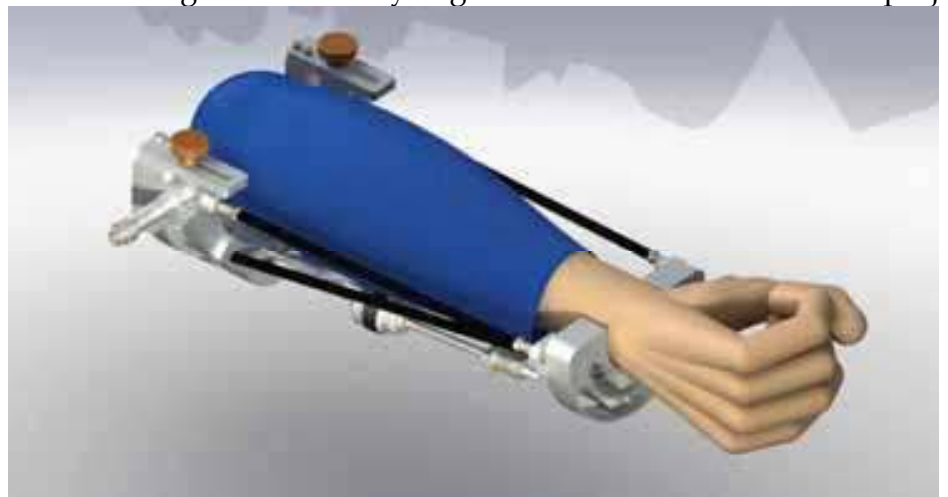

Fig. 23. A view of the forearm 1 axis structure and drive (SCS)

\subsection{Wrist articulation and drive}

The wrist is classically formed of two transversal perpendicular axis (equivalent of a U-joint) attached to the mobile arch. They are driven by a pair of SCS mounted on a structure that replaces one of the 3 rods of the parallel mechanism (Fig. 24).

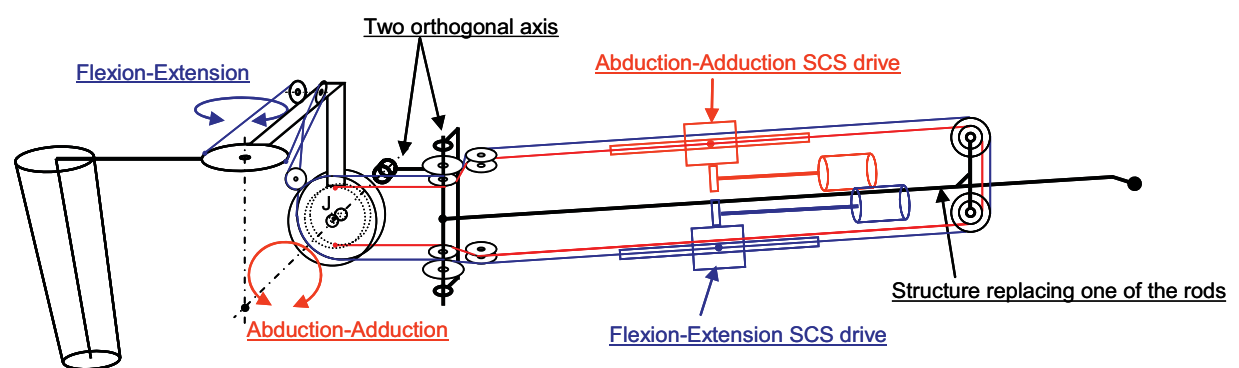

Fig. 24. Wrist 2 axis articulation and SCS drives with their respective cable routing

The examination of the routing of the cables indicates that there is a main linear coupling (red on blue) and also other non linear couplings of a low magnitude due to the deflexion of the cables through the two orthogonal axis (influence of the kinematics of the parallel linkage). The synergy of SCS actuators with the parallel linkage is potent because actuators can be harmoniously aligned with the rods and additionnally, the reflected inertia of the actuators is reduced because rod velocity decreases towards the fixed arch.

\subsection{Forearm and wrist structure}

Finally the structure is obtained by assembling the two precedent structures (Fig. 25). 


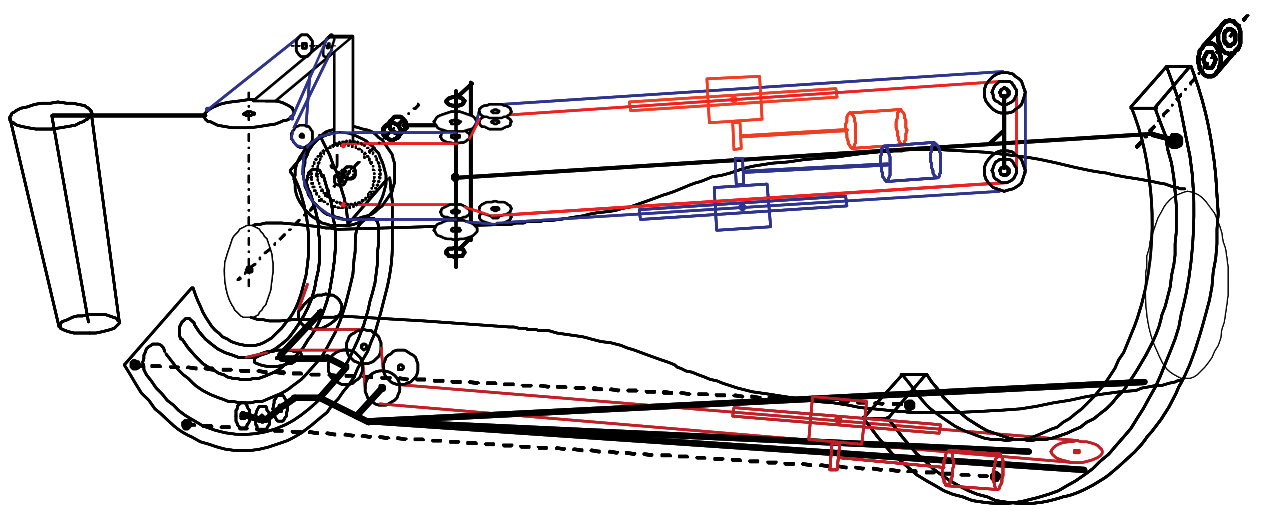

Fig. 25. Forearm and wrist 3 axis structure with its SCS drives

The heterogeneous linking devices on the mobile arch (two ball-joints on one hand and two orthogonal axis on the other hand) generate some other angular perturbations but fortunately of a low magnitude (below $1^{\circ}$ for our design) and again the cable transmission is able to absorb this tiny default. Because the chosen interface with the person is a handle, the human forearm will translate of about $6 \mathrm{~mm}$ relatively to the fixed arch. The absence of enclosure and the flexibility of the human skin should make it insensitive however. Fig. 26 shows the current project of a forearm-wrist unit planned for the 7 axis ABLE version.
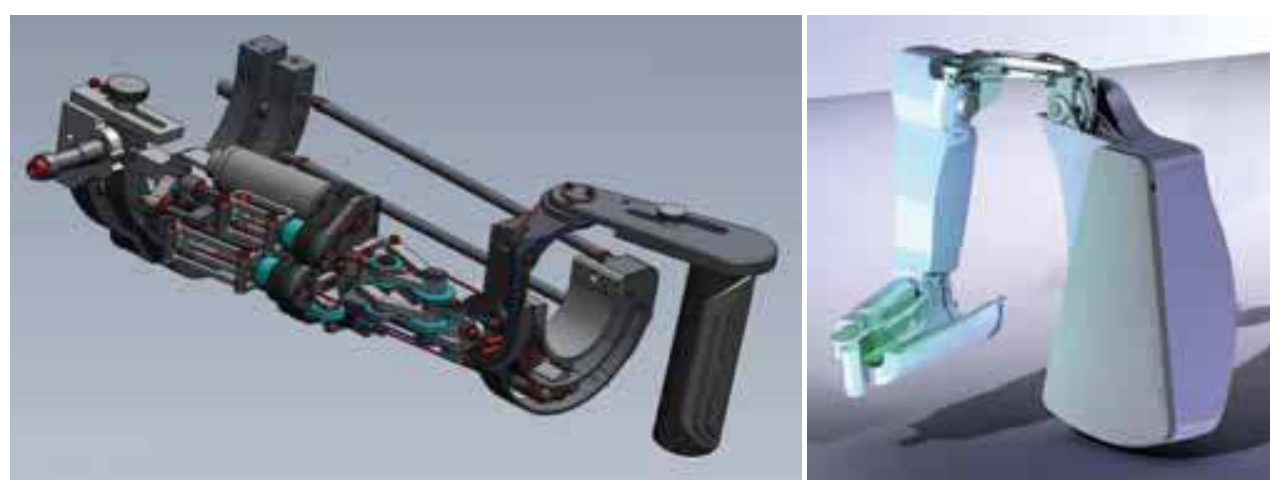

Fig. 26. Top, a view of the 3 axis forearm-wrist ; Bottom, a possible 7 axis ABLE equipped with the forearm-wrist

Finally, this new forearm-wrist mechanical structure is a lightweight open and truly anthropomorphic device, that provides a satisfactory amplitude for the critical pronosupination movement. The SCS integrates well in such a complex structure and guarantees a high linearity of force transmission paired with pretty high values of torque. 
Screw and cable actuators (SCS) and their applications

\begin{tabular}{|c|c|c|c|}
\hline MODULE & \multicolumn{2}{|c|}{ FOREARM-WRIST } & \\
\hline \multirow{2}{*}{ JOINT/ARTICULATION } & Axis 5 & Axis 6 & Axis 7 \\
\hline & Prono-supination & Abduction-Adduction & Flexion / Extension \\
\hline ARTICULATION & \multicolumn{3}{|c|}{ FOREARM } \\
\hline Amplitude & \multicolumn{3}{|c|}{$110^{\circ}$} \\
\hline Motors & \multicolumn{3}{|c|}{ DC ironless Faulhaber type } \\
\hline Transmission & \multicolumn{3}{|c|}{ Belt + Ball-screw and cable (SCS) } \\
\hline Ratio & 117 & 49 & 47 \\
\hline Max. velocity in hand (notional) & \multicolumn{3}{|c|}{$1 \mathrm{~m} / \mathrm{s}$} \\
\hline Joint torque (continuous) & $2 \mathrm{Nm}$ & $2 \mathrm{Nm}$ & $2 \mathrm{Nm}$ \\
\hline Continuous effort in hand (approx.) & $19 \mathrm{~N}$ & $22 \mathrm{~N}$ & $20 \mathrm{~N}$ \\
\hline No-load friction in hand (approx.) & \multicolumn{2}{|c|}{$0 \mathrm{~N}$} & $0 \mathrm{~N}$ \\
\hline
\end{tabular}

Table 5. Forearm-wrist main specifications

\section{Further development of ABLE and expansion of SCS applications to anthropomorphic robotics}

Furthermore, we suggest that derived versions of the above forearm mechanism could be used for low limb exoskeletons as well (Fig. 27).

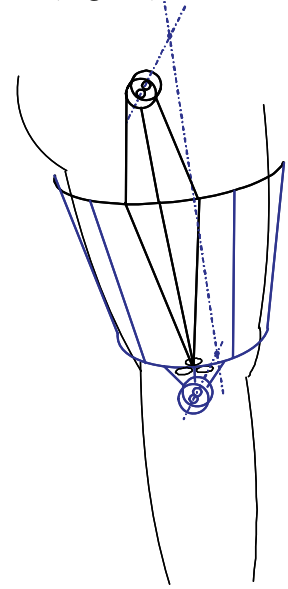

Fig. 27. Example of adaptation of a forearm-wrist mechanism to a low limb exoskeleton (thyknee articulation)

\section{Conclusion}

Less than a decade ago the SCS actuator technology was introduced in several prototypes and 2 industrial master arms have been since in used in various teleoperation systems at AREVA and CEA. Similar actuators have been successfully integrated in articulated architecture of the upper limb exoskeleton ABLE leading to an open and anthropomorphic machine. Evaluations are undergoing for its use as an orthosis for rehabilitation (Jarrassé et al. 2008). A new complete 7 axis version is also planned in 2010, to be used in a 
teleoperation/haptics context. These research projects will contribute to specify a multi-role exoskeleton with a higher potential for industrialization.

SCS actuators are also well adapted to anthropomorphic robots such as lightweight, assistive slave arms embeddable on a mobile platform, biped robots and low limb exoskeletons. Other industrial applications may envisioned, for example in the field of assistance devices to reduce musculoskeletal disorders.

However some more developmental work must be done to secure industrial applications. For example the control of cable tension should be ideally continuous along the life of the machine to allow a predictive maintenance. A software tool would be useful to facilitate the design of transmission cable in complex routings and the integration of all mechanical parameters of the cable to automatically compute the performances of the machine.

\section{References}

Bergamasco M., Allotta B., Bosio L., Ferretti L., Parrini G., Prisco G. M., Salsedo F., and Sartini G.," An arm exoskeleton system for teleoperation and virtual environments applications", in Proc. IEEE Int. Conf. Robot. Autom., vol. 2, 1994, pp. 1449-1454

Flatau C. R., "Development of Servo Manipulators for High Energy Accelerator Requirements' Proc. 13 ${ }^{\text {th }}$ Conf.Remote Sist. Technolol., 29, 1965

Flatau C. R., Vertut J."MA22-A compact bilateral servo master-slave manipulator", Proc. of 20th Conf. on Remote Systems Tech., 1972

Frisoli L., Borelli A., Montagner, et al,"Arm rehabilitation with a robotic exoskeleleton in Virtual Reality", Proc. of IEEE ICORR 2007, Intern. Conf. on Rehabilitation Robotics

Galbiati et al., "A Compact Flexible Servo System for Master Slave Electric Manipulator", 1964

Garrec P., "Systèmes mécaniques", in: Coiffet. P et Kheddar A., Téléopération et télérobotique, Ch 2., Hermes, Paris, France, 2002

Garrec P., French Patent: «Transmission à vis, écrou et câble attaché à la vis » for screw and nut transmission and cable - FR0101630, 2000 (EUR 01938347.0-2421 and US $10 / 296,740$

Garrec P., Friconneau J.P., Louveau F., "Virtuose 6D: A new force-control master arm using innovative ball-screw actuators", in Proceedings of ISIR 35th International Symposium in Robotics, Paris, March 2004

Garrec P., Martins J.P., Friconneau J.P., “A new Technology for Portable Exoskeletons”, AMSE 2004 - Vol. 65 n 7/8, pp 13-22.

Garrec P., Martins J.P., Gravez, Perrot Y., Measson Y., "A New Force-Feedback, Morphologically Inspired Portable Exoskeleton" Proceedings of 15th IEEE International Symposium on Robot and Human Interactive Communication (ROMAN - 2006), September 2006, Hatfield, UK.

Goertz R. C. et al., "Master-Slave Servo-Manipulator" Model 2", Proc.4th Ann. Conf. Hot Lab. And Equip. 1, 1955

Goubot J.M., Garrec P., "STeP: an innovative teleoperation system for decommissioning operations", Workshop "Decommissioning challenges: An industrial reality ?", French Nuclear Energy Society, 23-28 November 2003, Avignon, France 
Screw and cable actuators (SCS) and their applications

Gupta A., O'Malley M.K.," Design of a haptic arm exoskeleton for training and rehabilitation", Mechatronics, IEEE/ASME Transactions on Volume 11, Issue 3, June 2006 Page(s):280 - 289

Köhler G.-W., « Manipulator Type Book », Verlag Karl Thiemig, München, 1981

Perry J.C., Rosen J., Burns S., “Upper-Limb Powered Exoskeleton Design”, IEEE/ASME Transactions on Mechatronics, Volume 12, Issue 4, Aug. 2007 Page(s):408 - 417

Vertut J., and al."Bilateral Servo Manipulator MA23 in Direct Mode and Via Optimized Computer Control" 2nd Remotely Manned Syst. Technol.Conf., 1975

Vertut J., Coiffet P., Téléopération «Evolution des techniques », vol. 3A, Hermes, Paris France, 1984 


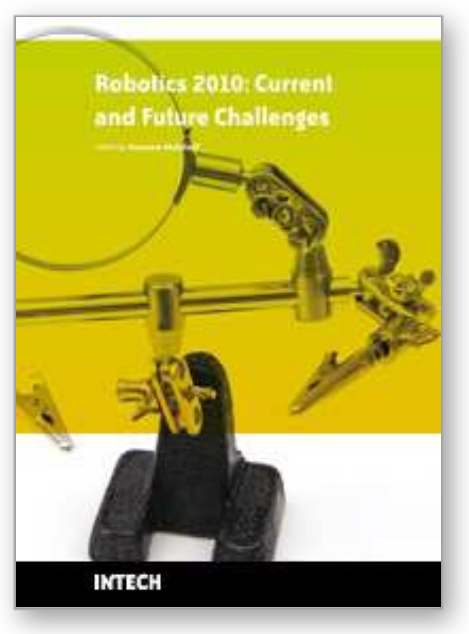

\section{Robotics 2010 Current and Future Challenges \\ Edited by Houssem Abdellatif}

ISBN 978-953-7619-78-7

Hard cover, 494 pages

Publisher InTech

Published online 01, February, 2010

Published in print edition February, 2010

Without a doubt, robotics has made an incredible progress over the last decades. The vision of developing, designing and creating technical systems that help humans to achieve hard and complex tasks, has intelligently led to an incredible variety of solutions. There are barely technical fields that could exhibit more interdisciplinary interconnections like robotics. This fact is generated by highly complex challenges imposed by robotic systems, especially the requirement on intelligent and autonomous operation. This book tries to give an insight into the evolutionary process that takes place in robotics. It provides articles covering a wide range of this exciting area. The progress of technical challenges and concepts may illuminate the relationship between developments that seem to be completely different at first sight. The robotics remains an exciting scientific and engineering field. The community looks optimistically ahead and also looks forward for the future challenges and new development.

\section{How to reference}

In order to correctly reference this scholarly work, feel free to copy and paste the following:

Phillipe Garrec (2010). Screw and Cable Acutators (SCS) and Their Applications to Force Feedback Teleoperation, Exoskeleton and Anthropomorphic Robotics, Robotics 2010 Current and Future Challenges, Houssem Abdellatif (Ed.), ISBN: 978-953-7619-78-7, InTech, Available from: http://www.intechopen.com/books/robotics-2010-current-and-future-challenges/screw-and-cable-acutatorsscs-and-their-applications-to-force-feedback

\section{INTECH}

open science | open minds

\author{
InTech Europe \\ University Campus STeP Ri \\ Slavka Krautzeka 83/A \\ 51000 Rijeka, Croatia \\ Phone: +385 (51) 770447 \\ Fax: +385 (51) 686166 \\ www.intechopen.com
}

\author{
InTech China \\ Unit 405, Office Block, Hotel Equatorial Shanghai \\ No.65, Yan An Road (West), Shanghai, 200040, China \\ 中国上海市延安西路65号上海国际贵都大饭店办公楼 405 单元 \\ Phone: +86-21-62489820 \\ Fax: +86-21-62489821
}


(C) 2010 The Author(s). Licensee IntechOpen. This chapter is distributed under the terms of the Creative Commons Attribution-NonCommercial-ShareAlike-3.0 License, which permits use, distribution and reproduction for non-commercial purposes, provided the original is properly cited and derivative works building on this content are distributed under the same license. 